\title{
Burden of informal care in stroke survivors and its determinants: a prospective observational study in an Asian setting
}

Yi Wang ${ }^{1}$, Shilpa Tyagi ${ }^{1}$, Helen Hoenig ${ }^{2}$, Kim En Lee ${ }^{3}$, Narayanaswamy Venketasubramanian $^{4}$, Edward Menon ${ }^{5}$, Deidre Anne De Silva ${ }^{6}$, Philip Yap ${ }^{7}$, Boon Yeow Tan ${ }^{8}$, Sherry H. Young ${ }^{9}$, Yee Sien $\mathrm{Ng}^{10}$, Tian Ming $\mathrm{Tu}^{11}$, Yan Hoon Ang ${ }^{7}$, Keng He Kong ${ }^{12}$, Rajinder Singh ${ }^{11}$, Reshma A. Merchant ${ }^{13}$, Hui Meng Chang ${ }^{6}$, Chou Ning ${ }^{14}$, Angela Cheong ${ }^{1}$ and Gerald Choon-Huat Koh ${ }^{1 *}$

\begin{abstract}
Background: Informal caregiving is an integral part of post-stroke recovery with strenuous caregiving demands often resulting in caregiving burden, threatening sustainability of caregiving and potentially impacting stroke survivor's outcomes. Our study aimed to examine and quantify objective and subjective informal care burden after stroke; and to explore the factors associated with informal care burden in Singapore.

Methods: Stroke patients and their informal caregivers were recruited from all five tertiary hospitals in Singapore from December 2010 to September 2013. Informal care comprised of assistance provided by informal caregivers with any of the activities of daily living. Informal care burden was measured by patients' likelihood of requiring informal care, hours of informal care required, and informal caregivers' Zarit's Burden Score. We examined informal care burden at 3-months and 12-months post-stroke. Generalized linear regressions were applied with control variables including patients' and informal caregivers' demographic characteristics, arrangement of informal care, and patients' health status including stroke severity (measured using National Institute of Health Stroke Scale), functional status (measured using Modified Rankin Scale), selfreported depression, and common comorbidities.
\end{abstract}

\footnotetext{
* Correspondence: ephkohch@nus.edu.sg

'Saw Swee Hock School of Public Health, National University of Singapore,

12 Science Drive 2, \#10-01, Singapore 117549, Singapore

Full list of author information is available at the end of the article
}

(c) The Author(s). 2021 Open Access This article is licensed under a Creative Commons Attribution 4.0 International License, which permits use, sharing, adaptation, distribution and reproduction in any medium or format, as long as you give appropriate credit to the original author(s) and the source, provide a link to the Creative Commons licence, and indicate if changes were made. The images or other third party material in this article are included in the article's Creative Commons licence, unless indicated otherwise in a credit line to the material. If material is not included in the article's Creative Commons licence and your intended use is not permitted by statutory regulation or exceeds the permitted use, you will need to obtain permission directly from the copyright holder. To view a copy of this licence, visit http://creativecommons.org/licenses/by/4.0/. The Creative Commons Public Domain Dedication waiver (http://creativecommons.org/publicdomain/zero/1.0/) applies to the data made available in this article, unless otherwise stated in a credit line to the data. 
Results: Three hundred and five patients and 263 patients were examined at 3-months and 12-months. Around 35\% were female and 60\% were Chinese. Sixty three percent and $49 \%$ of the patients required informal care at 3-months and 12-months point, respectively. Among those who required informal care, average hours required per week were $64.3 \mathrm{~h}$ at 3 -months and $76.6 \mathrm{~h}$ at 12 -months point. Patients with higher functional dependency were more likely to require informal care at both time points, and required more hours of informal care at 3-months point. Female informal caregivers and those caring for patients with higher functional dependency reported higher Zarit's Burden. While informal caregivers who worked full-time reported higher burden, those caring for married stroke patients reported lower burden at 3-months point. Informal caregivers who co-cared with foreign domestic workers, i.e.: stay-in migrant female waged domestic workers, reported lower burden.

Conclusions: Informal care burden remains high up to 12-months post-stroke. Factors such as functional dependency, stroke severity, informal caregiver gender and co-caring with foreign domestic workers were associated with informal care burden.

Keywords: Informal care, Quality of life, Rehabilitation, Stroke, Stroke management, Socio-economic factors

\section{Background}

Globally, stroke ranked third in causing years of life lost in 2017 [1]. The high magnitude of economic burden of stroke has been reported in many countries [2-6]. In Singapore, stroke is one of the leading contributors to the burden of disease [7]. Direct medical cost due to stroke imposes considerable economic burden in Singapore [8].

Informal caregivers, the role usually played by family members, close relatives or friends, are often required to assist patients at home with their post-stroke care needs. Significant amount of time can be required from informal caregivers $[9,10]$. A study in Spain found that average daily hours required for informal care were $8.7 \mathrm{~h} 3$ months post stroke and $7.2 \mathrm{~h} 12$ months post stroke [10]. From the societal perspective, this can impose considerable economic strain [11-13]. A study based in UK reported that the cost of one stroke to NHS increased to $£ 29,405$ from $£ 15,306$ over 5 years when informal caregiving costs were incorporated [14]. Another estimate from the US suggested the national burden of informal caregiving associated with injurious falls in stroke survivors to be $\$ 2.9$ billion [15]. The total national economic burden associated with informal caregiving post-stroke was reported to be $\$ 14.2$ billion in another US based study [16].

At the same time, informal caregivers may experience stress, strain and decreased quality of life [17-20]. Factors affecting informal care burden have been explored in the literature with mixed results. Association between higher functional dependency of the patients and the higher informal caregivers' burden was found in some studies $[9,10,21]$ but not in others [22]. More hours of care provided [10, 18], higher number of tasks [17], and worse patients' mental health $[9,19]$ were found to be associated with higher informal caregivers' strain. Patients' and informal caregivers' demographic characteristics were also reported to be associated with the burden in some studies [23, 24]. Family support and patients' factors $[18,19]$ were found to be associated with informal caregivers' burden at some specific time points after stroke but not the other time points.

Though the literature is abundant, no such study has been conducted in Singapore examining the informal care burden post-stroke and its potential determinants. In Singapore, patients with stroke symptoms usually seek care at the emergency department of any of the public tertiary hospitals after which they are admitted for appropriate treatment. Once stabilized in acute care setting, they can either be discharged to a step-down setting (locally known as community hospitals) or discharged home. The average length of stay after stroke in such public tertiary hospitals is reported to be about 7.7 days [25]. While in acute care setting, stroke survivors are also assessed for eligibility for rehabilitation and based on this assessment they may undergo intensive rehabilitation in an inpatient setting. Alternatively, they may be referred to supervised community rehabilitation (either after inpatient rehabilitation or as an alternative to the same), often delivered at the day rehabilitation centres spread across whole of Singapore. It has been reported previously that more than $70 \%$ of the stroke survivors are discharged home from acute care setting [26], highlighting the relevance of informal care provided at home. Different from Western settings, foreign domestic workers (FDWs) can be employed in Singapore to help care for patients with stroke. A FDW is "a stay-in migrant female waged domestic worker attached to one employer and works for only a single household, under Singapore's strict legal permit system" [27]. They are usually hired to provide assistance in daily housework. 
When households' members get sick, the FDWs can play important roles in informal caregiving [28].

From a societal perspective, quantifying informal care burden is important to estimate the total cost of stroke. Moreover, highlighting the determinants of informal care burden along with its magnitude can contribute to designing policies and social support interventions to help patients and their informal caregivers post-stroke. To address the aforementioned gaps, this study aimed to examine burden of informal care of patients with stroke and its potential determinants at 3-months point and 12 -months point post-stroke in Singapore. Specific objectives of the study are as follows: (1) to quantify the hours of informal caregiving reported at 3-months point and 12-months point post stroke, (2) to examine the determinants of receiving informal care, (3) to examine the determinants of amount of informal care received and (4) to examine the determinants of informal caregiver burden reported at 3-months point and 12-months point post stroke.

\section{Methods}

\section{Data sources}

Singapore Stroke Study (S3) was a yearlong prospective study in Singapore with the recruitment period from December 2010 to September 2013. Stroke patients and their informal caregivers were recruited from all five tertiary hospitals in Singapore. Stroke patients were eligible if they were: (i) Singaporean or permanent resident, more than 40 years old and residing in Singapore for the next 1 year, (ii) stroke must be a recent diagnosis (i.e. stroke symptoms occurring within 4 weeks prior to admission) with diagnosis made by a clinician and/or supported by brain imaging (CT or MRI) and (iii) not globally aphasic. An informal caregiver could be an immediate or extended family member or friend, more than 21 years (the legal definition of adult in Singapore), providing care or assistance of any kind and taking responsibility for the patient, as recognized by the patient and not fully paid for caregiving. We defined the informal caregivers that participated S3 as corresponding informal caregivers. FDWs were not eligible to be corresponding informal caregivers. S3 was approved by the National University of Singapore Institutional Review Board, SingHealth Centralized Institutional Review Board and the National Health Group Domain Specific Review Board. Written informed consent was obtained from both the patients and informal caregivers. Further details of S3 are reported elsewhere [29].

\section{Data collection}

Patients and corresponding informal caregivers were interviewed face-to-face at baseline, 3-months point, and 12-months point post stroke. Corresponding informal caregivers were also interviewed by phone at 6-months point and 9-months point. Information collected included patients' and corresponding informal caregivers' demographics, healthcare resource utilization, healthrelated information for both patients and corresponding informal caregivers, and time spent caring for stroke patients by the assisting informal caregivers defined as the informal caregivers that provided informal care in assisting stroke patients with their daily activities. A corresponding informal caregiver may or may not be an assisting informal caregiver. For example, the corresponding informal caregiver could provide other types of assistance such as financial assistance or monitoring the FDWs to assist patients with their daily activities. Overtime, some of the patients no longer required informal care. The corresponding informal caregivers were still followed up to collect data.

Standardised questionnaires and forms, piloted using 40 participants, were used to collect data. The interviews were conducted by a team of research assistants, who underwent a 3-days training to learn about the content and right method of administering the survey and interview. To maximise response rates, efforts were made to accommodate participants' schedules and reminders were sent out before each interview. Multiple attempts (up to three) were made to reach out to participants.

This work used data collected at 3-months point and 12-months point, when information from both patients and corresponding informal caregivers were available.

\section{Dependent variables}

The dependent variables included hours of informal care received by the patients and the Zarit's Burden Score [30] of corresponding informal caregivers. While informal care was defined as "providing care or assistance of any kind and taking responsibility for the patient, as recognized by the patient and not fully paid for caregiving" when recruiting corresponding informal caregivers, in this work, we focused on examining burden due to informal care comprising of assistance provided by the assisting informal caregivers with any of the activities of daily living (i.e.: doing light housework, preparing meals, eating, bathing or showering, dressing, using the toilet, getting in or out of a bed or chair, walking, using private or public transport, shopping, using the telephone, taking medicine as prescribed, and minor healthcare activities which do not require medical training etc.) in the past 3 months due to any physical or mental health problem experienced by the stroke survivor. For each patient, the corresponding informal caregiver reported the average hours of informal care per week provided by all the assisting informal caregivers during the past 3 months at 3-months point and 12-months point. For each assisting informal caregiver, we capped the hours 
of care provided per week at $84 \mathrm{~h}$. We added up the average weekly hours provided by all the assisting informal caregivers to generate the total number of "personhours" of care received by each patient per week.

Corresponding informal caregiver's appraisal of caregiving burden was captured by the Zarit's Burden Interview, which involved asking corresponding informal caregivers to rate how often they felt several negatively phrased questions related to their caregiving role [31]. Validated previously in Singapore [32], we used the abbreviated 12-item version for the current study with a total score ranging from 0 to 48. Higher score implied higher burden. Different cut-offs, such as $13,17,18$, have been proposed in the literature to detect caregivers with high or severe burden [33-35]. To avoid making arbitrary decision in cut-off point and avoid loss of information associated with dividing continuous variables into categories, we kept Zarit's Burden Score as continuous variable in this study.

Zarit's Burden Interview was one part of the survey questions for the corresponding informal caregivers in S3. The corresponding informal caregivers can choose not to answer the Zarit's Burden Interview if they did not provide any informal care. In this work, we focused on the burden due to assistance with stroke patients' daily activities. Zarit's Burden Score were only examined for the corresponding informal caregivers who were assisting informal caregivers and assisted stroke patients with their daily activities.

\section{Independent variables}

Guided by the literature, independent variables selected included patients' and corresponding caregivers' demographic characteristics [23, 24]; patients' level of dependency, severity of stroke, and other comorbidities [9, 10, 21]; patients' mental health [9]; hours of informal care provided by the assisting informal caregivers and co-caring with other assisting informal caregivers $[18,20]$. Co-caring with FWDs was also included to fit Singapore's context. Comorbidities collected in S3 included cardiovascular disease, diabetes, hypertension, hyperlipidemia, chronic lung disease, dementia, autoimmune disease, leukaemia, liver disease, malignant solid tumor, and renal disease. Common comorbidities including cardiovascular disease, diabetes, hypertension, and hyperlipidemia were included in the analysis. Patients were categorized as either having or not having the corresponding comorbidities. The remaining comorbidities were not included in the analysis due to very low prevalence rate among the S3 patients.

For patients, demographic information including age, gender, ethnicity, and marital status were used. Ward class recorded at recruitment was used as a proxy for socio-economic status of the patients. There are four types of ward classes in public hospitals in Singapore, A, $\mathrm{B} 1, \mathrm{~B} 2$ and $\mathrm{C}$, with increasing level of subsides. The quality of care across 4 classes is similar, but the level of amenities differs. For example, ward class $\mathrm{C}$ has up to 8 beds in a room. Ward class A is a single room with attached bathroom and toilet, television, fully automated electric bed, choice of meal, and sleeper unit for accompanying adult at additional charge. The daily rate for different wards are around 35 SGD ( 26 USD) for ward class C, 79 SGD ( 59 USD) for ward class B2, 251 SGD $(\sim 186$ USD) for ward class B1, and 466 SGD $(\sim 346$ USD) for ward class A. Patients and/or patients' representatives can choose the ward class to stay. Patients living in ward class B1 and A were expected to have higher social economic status compared to patients living in ward class B2 and ward class C. Modified Rankin Scale (MRS) [36] measured at 3-months point and 12-months point were used to measure the level of disability and dependence of the patients. The score was classified into 3 categories in this study: no symptoms or no significant disability despite symptoms (0-1), slight disability or moderate disability (2-3), and moderately severe disability or severe disability (4-5). National Institute of Health Stroke Scale (NIHSS) [37] and other comorbidities including cardiovascular disease, diabetes, hypertension, and hyperlipidaemia collected at recruitment were used. NIHSS was classified into 2 categories in this study: moderate to severe stroke with score equal and higher than 5, and mild with score less than 5. Information of whether the patients' self-reporting depressive symptoms at 3-months point and 12-months point were also used.

For corresponding informal caregivers who were interviewed, their gender, age, ethnicity, and marital status were collected. Corresponding informal caregivers reported their relationship with the patients and their working status, as well as of the other assisting informal caregivers who provided care to the patients.

\section{Statistical analysis}

While descriptive statistics of person-hours of informal care provided were presented for all the assisting informal caregivers, Zarit's Burden Score was only summarized and examined using regression analysis for the corresponding informal caregivers who were assisting informal caregivers at the same time. Multivariable regression analysis was conducted to examine the factors associated with informal care burden at 3-months point and 12-months point. Logistic regression was used to examine the requirement of informal care. Generalized linear regression was used to examine the hours of informal care required and the Zarit's Burden Score. In all the analyses, a full model including all the relevant control variables was used first. A parsimonious model was then generated by iteratively removing the most insignificant control variables until all the variables were with $p<0.10$. However, we maintained patients' demographic 
information, informal caregivers' demographic information, and patients' MRS in the parsimonious specification regardless of the $p$-value. We reported the results from parsimonious models in the main text. The results from full models can be found from Supplemental Material Table III and Table IV. All analyses were conducted using Stata Statistical Software: Release 16 [38].

\section{Results}

At the baseline, 661 patients with stroke were recruited. After removing patients and corresponding informal caregivers with missing information, 305 (46\%) and 263 (40\%) patients were used to analyse the hours of care at 3-months point and 12-months point, respectively. For the Zarit's Burden Score, the number of corresponding informal caregivers, who were assisting informal caregivers at the same time, were 168 at 3-months point and 101 at 12-months point. We used the term assisting informal caregivers when discussing the results on Zarit's Burden Score to highlight the burden was driven by informal care in assisting stroke patients with their daily activities. The study flowchart was presented in Fig. 1.
Table 1 shows the demographic information of patients and corresponding informal caregivers included in the analysis for hours of care. Distribution of patients' gender, age, ethnicity, marital status, ward class, were similar at 3-months points and 12-months points based on statistical tests. Majority of the stroke patients were male, $66.6 \%$ at 3 -months point and $65.0 \%$ at 12 months point. Fifty nine point $7 \%$ of the patients were Chinese at 3-months point and $63.1 \%$ of patients were Chinese at 12-months point. Majority of the patients were married. At 3-months point, $27.5 \%$ of the patients were with slight or moderate disability; and $18.4 \%$ of the patients were with moderate severe or severe disability. At 12 -months point, $22.1 \%$ of the patients were with slight or moderate disability; and $16.7 \%$ of the patients were with moderate severe or severe disability. Available information at recruitment was also presented to understand the participants without followups or with missing information. Characteristics, that were significantly different between the participants that were followed up and not followed up, were highlighted. Detailed comparison was presented in Supplemental Material Table I.

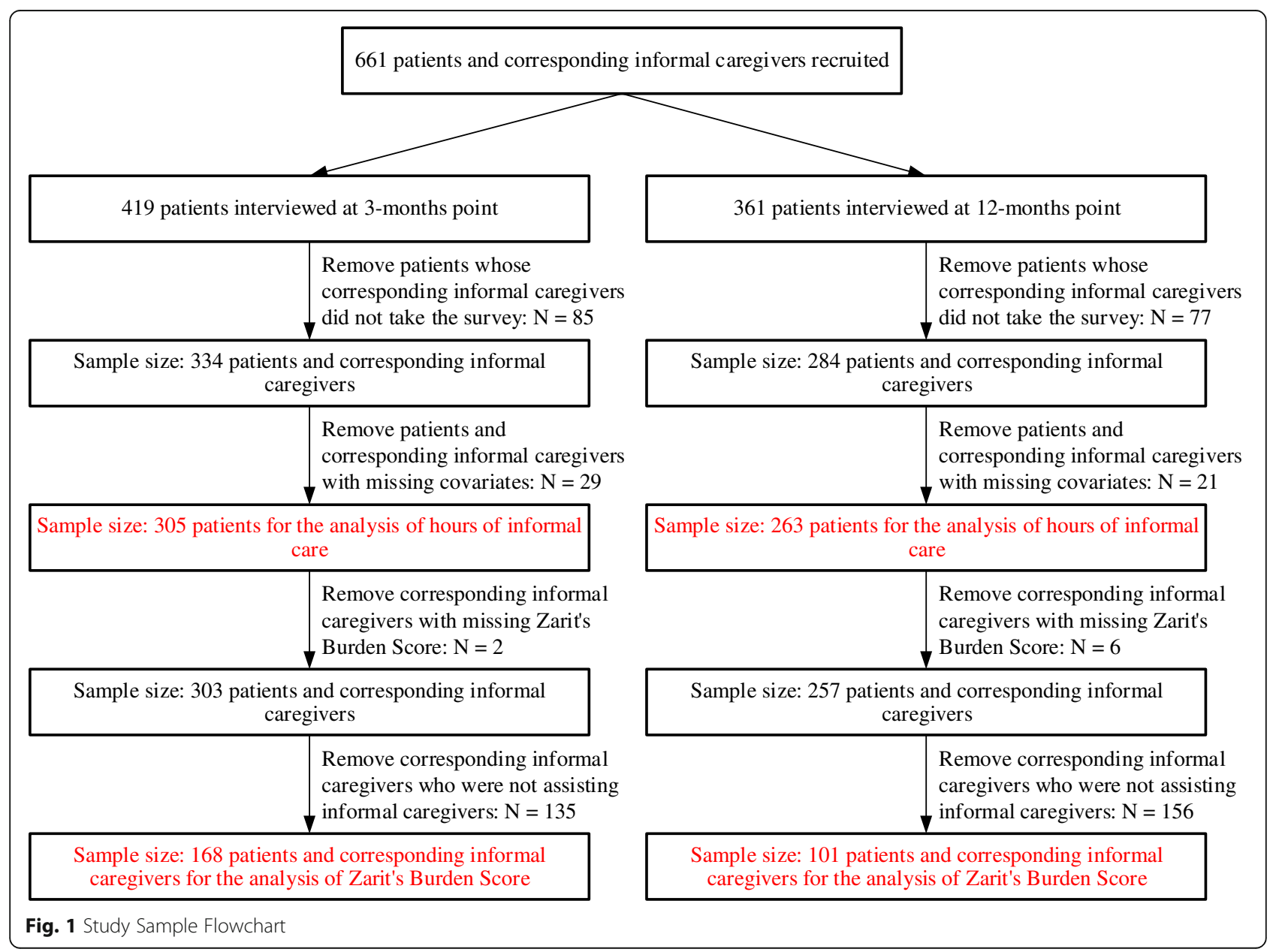


Table 1 Summary Statistics of Demographic Information

\begin{tabular}{|c|c|c|c|}
\hline & $\begin{array}{l}\text { 3-months point } \\
\text { post-stroke, } \\
\text { Number (\%) }\end{array}$ & $\begin{array}{l}\text { 12-months point } \\
\text { post-stroke, } \\
\text { Number }(\%)\end{array}$ & $\begin{array}{l}\text { At recruitment, } \\
\text { Number (\%) }\end{array}$ \\
\hline \multicolumn{4}{|l|}{ Patients } \\
\hline Number & 305 & 263 & 661 \\
\hline \multicolumn{4}{|l|}{ Gender } \\
\hline Male & $203(66.6 \%)$ & $171(65.0 \%)$ & $437(66.1 \%)$ \\
\hline Female & $102(33.4 \%)$ & $92(35.0 \%)$ & $224(33.9 \%)$ \\
\hline \multicolumn{4}{|l|}{ Age } \\
\hline$<=50$ & $35(11.7 \%)$ & $33(12.7 \%)$ & $90(13.6 \%)$ \\
\hline $51-65$ & $150(47.0 \%)$ & $133(48.9 \%)$ & $321(48.6 \%)$ \\
\hline$>65$ & $120(41.3 \%)$ & 97 (38.4\%) & $250(37.8 \%)$ \\
\hline \multicolumn{4}{|l|}{ Ethnicity } \\
\hline Chinese & $182(59.7 \%)^{*}$ & $166(63.1 \%)$ & $446(67.5 \%)$ \\
\hline Malay, Indian, and others & $123(40.3 \%)^{*}$ & 97 (36.9\%) & $215(32.5 \%)$ \\
\hline Married & $239(78.4 \%)^{*}$ & $204(77.6 \%)^{*}$ & $452(68.4 \%)$ \\
\hline \multicolumn{4}{|l|}{ Ward class } \\
\hline (Unsubsidized) A \& B1 & $20(6.6 \%)$ & $17(6.4 \%)$ & $48(7.3 \%)$ \\
\hline (Subsidized) B2 & $138(45.2 \%)$ & $123(46.8 \%)$ & 285 (43.1\%) \\
\hline (Subsidized) C & $147(48.2 \%)$ & $123(46.8 \%)$ & $328(49.6 \%)$ \\
\hline \multicolumn{4}{|l|}{ Modified Rankin Scale } \\
\hline $\begin{array}{l}\text { No symptoms or No significant disability despite } \\
\text { symptoms }(0-1)\end{array}$ & $165(54.1 \%)$ & $161(61.2 \%)$ & NA \\
\hline Slight disability or Moderate disability (2-3) & $84(27.5 \%)$ & $58(22.1 \%)$ & NA \\
\hline Moderate severe disability or severe disability (4-5) & $56(18.4 \%)$ & $44(16.7 \%)$ & NA \\
\hline Depressed & $96(31.5 \%)$ & $56(21.3 \%)$ & NA \\
\hline First-time stroke & $248(81.3 \%)$ & $213(81.0 \%)$ & $533(80.8 \%)$ \\
\hline \multicolumn{4}{|l|}{ NIHSS score at recruitment } \\
\hline No stroke symptom or minor stroke (0-4) & $165(54.1 \%)^{*}$ & $146(55.5 \%)$ & $373(60.0 \%)$ \\
\hline Moderate, moderate severe, or sever stroke (5-42) & $140(45.9 \%)^{*}$ & $117(44.5 \%)$ & $249(40.0 \%)$ \\
\hline \multicolumn{4}{|l|}{ Other comorbidities at recruitment } \\
\hline Cardiovascular disease & $60(19.7 \%)$ & $45(17.1 \%)$ & $121(18.3 \%)$ \\
\hline Diabetes & $133(43.6 \%)$ & $118(44.9 \%)$ & $274(41.5 \%)$ \\
\hline Hypertension & $220(72.1 \%)$ & $197(74.9 \%)$ & $480(72.6 \%)$ \\
\hline Hyperlipidemia & $222(72.8 \%)$ & $185(70.3 \%)$ & $473(71.6 \%)$ \\
\hline \multicolumn{4}{|l|}{ Corresponding Informal Caregivers } \\
\hline Number & 305 & 263 & NA \\
\hline \multicolumn{4}{|l|}{ Gender } \\
\hline Male & 77 (25.3\%) & $66(25.1 \%)$ & NA \\
\hline Female & $228(74.7 \%)$ & $197(74.9 \%)$ & NA \\
\hline \multicolumn{4}{|l|}{ Age } \\
\hline$<=50$ & 137 (44.9\%) & 115 (43.7\%) & NA \\
\hline $51-65$ & $126(41.3 \%)$ & 105 (39.9\%) & NA \\
\hline$>65$ & 42 (13.8\%) & 43 (16.4\%) & NA \\
\hline \multicolumn{4}{|l|}{ Ethnicity } \\
\hline Chinese & 181 (59.3\%) & $164(62.4 \%)$ & NA \\
\hline
\end{tabular}


Table 1 Summary Statistics of Demographic Information (Continued)

\begin{tabular}{llll}
\hline & $\begin{array}{l}\text { 3-months point } \\
\text { post-stroke, } \\
\text { Number (\%) }\end{array}$ & $\begin{array}{l}\text { 12-months point } \\
\text { post-stroke, } \\
\text { Number (\%) }\end{array}$ & $\begin{array}{c}\text { At recruitment, } \\
\text { Number (\%) }\end{array}$ \\
\hline $\begin{array}{l}\text { Malay, Indian, and others } \\
\text { Married }\end{array}$ & $124(40.7 \%)$ & $99(37.6 \%)$ & NA \\
Relationship with Patients & $241(79.0 \%)$ & $212(81.5 \%)$ & NA \\
$\begin{array}{l}\text { Spouse } \\
\text { Children, children-in-law, grandchildren }\end{array}$ & $178(58.4 \%)$ & $126(64.0 \%)$ & $\mathrm{NA}$ \\
$\begin{array}{l}\text { Parents } \\
\text { Other relatives and friends } \\
\text { Living in the same house with the patients }\end{array}$ & $99(32.5 \%)$ & $55(27.9 \%)$ & $\mathrm{NA}$ \\
\hline
\end{tabular}

Notes: * The characteristic are significantly different at $5 \%$ between the participants that were followed-up and not followed-up. Detailed comparison can be found in Supplemental Material Table I

Table 2 shows the summary statistics about informal care burden. Among all the patients, $62.6 \%$ required informal care over the last 3 months as reported at 3months interview and $48.7 \%$ required informal care over the last 3 months as reported at 12-months interview. Among the patients that required informal care, the average hours per week required were $64.3 \mathrm{~h}$ at 3months point and $76.6 \mathrm{~h}$ at 12 -months point. The median hours per week required were $56 \mathrm{~h}$ at 3 -months point and $60 \mathrm{~h}$ at 12 -months point. The total number of informal caregivers involved in caring for the patients during the past 3 months were 324 at 3 -months point and 246 at 12 -months point. Additional information on the hours of informal care provided per informal caregiver and the histogram of hours of informal care provided per week were presented in Supplemental Material

Table 2 Summary Statistics for Informal Care Burden in the Past 3 Months

\begin{tabular}{|c|c|c|}
\hline & $\begin{array}{l}\text { 3-months point } \\
\text { post-stroke, } \\
\text { Number (\%) }\end{array}$ & $\begin{array}{l}\text { 12-months point } \\
\text { post-stroke, } \\
\text { Number (\%) }\end{array}$ \\
\hline Number of patients & 305 & 263 \\
\hline Number of patients required informal care & $191(62.6 \%)$ & $128(48.7 \%)$ \\
\hline \multicolumn{3}{|l|}{ Hours required per week per patient for those who required informal care } \\
\hline Mean (SD) & 64.3 (52.9) hours & $76.6(78.2)$ hours \\
\hline Median (5th percentile, 95th percentile) & $56(7,182)$ hours & $60(7,189)$ hours \\
\hline \multicolumn{3}{|l|}{$\begin{array}{l}\text { Number of assisting informal caregivers per patient for those who required } \\
\text { informal care }\end{array}$} \\
\hline 1 & $99(51.8 \%)$ & $65(50.8 \%)$ \\
\hline 2 & $58(30.4 \%)$ & $28(21.9 \%)$ \\
\hline 3 and above & $34(17.8 \%)$ & $35(27.3 \%)$ \\
\hline \multicolumn{3}{|l|}{ FDWs as assisting informal caregivers } \\
\hline \multicolumn{3}{|l|}{1 assisting informal caregiver: } \\
\hline Non-FDW & $90(47.1 \%)$ & $59(46.1 \%)$ \\
\hline FDW & $9(4.7 \%)$ & $6(4.7 \%)$ \\
\hline \multicolumn{3}{|l|}{ More than 1 assisting informal caregiver } \\
\hline Without FDW & $55(28.8 \%)$ & $51(39.8 \%)$ \\
\hline With FDW & $37(19.4 \%)$ & $12(9.4 \%)$ \\
\hline \multicolumn{3}{|l|}{ Zarit's Burden Score of assisting informal caregivers } \\
\hline $\begin{array}{l}\text { Number of corresponding informal caregivers who were assisting } \\
\text { informal caregivers }\end{array}$ & 168 & 101 \\
\hline Mean (SD) & $9.2(7.6)$ & $8.6(7.9)$ \\
\hline Median (5th percentile, 95th percentile) & $8(0,22)$ & $7(0,22)$ \\
\hline
\end{tabular}


Table II and Fig. I. The total hours of informal care per week could be greater than the total number of hours per week for the patients with more than 1 assisting informal caregiver.

Among the patients who required informal care, 168 out of their $191(88.0 \%)$ corresponding informal caregivers and 101 out of their $128(78.9 \%)$ corresponding informal caregivers were assisting informal caregivers at 3-months point and 12-months point respectively. The mean and median for Zarit's Burden Score were 9.2 and 8 at 3-months point. At 12-months point, the mean and median for Zarit's Burden Score were 8.6 and 7. Assisting informal caregivers reported higher burden at 3months point compared to 12-months point. Histogram of Zarit's Burden Score was presented in Supplemental Material Fig. II.

Table 3 shows results examining the factors associated with requiring informal care and hours of informal care required. Higher MRS was associated with higher likelihood of requiring informal care at both 3 -months point and 12-months point. At 3-months point, compared with patients with no symptom or disability, the odds ratio (OR) of requiring informal care was 2.69 (95\%-CI = $(1.43,5.06))$ and $6.33(95 \%-\mathrm{CI}=(2.44,16.40))$ for patients with slight or moderate disability and moderate severe or severe disability, respectively. At 12-months point, compared with patients with no symptom or disability, the OR of requiring informal care was 3.58 (95\%$\mathrm{CI}=(1.84,6.94))$ and $10.63(95 \%-\mathrm{CI}=(4.33,26.05))$ for patients with slight or moderate disability and moderate severe or severe disability, respectively.

At 3-months point, compared to patients with no symptom or disability, patients with slight or moderate disability and patients with moderate severe or severe disability required more hours of informal care per week. Patients with moderate to severe stroke also required more hours of informal care per week (Coef $=0.35$, 95\%$\mathrm{CI}=(0.09,0.60))$. Compared to male patients, female patients required more hours of informal care $($ Coef $=0.27$, $95 \%-\mathrm{CI}=(0.001,0.65))$ at 3 -months point. At 12 -months

Table 3 Regression: Factors associated with Requirement of Informal Care and Hours of Informal Care - Parsimonious Model

\begin{tabular}{|c|c|c|c|c|}
\hline & \multicolumn{2}{|l|}{ 3-Months Point } & \multicolumn{2}{|l|}{ 12-Months Point } \\
\hline & $\begin{array}{l}\text { Requirement of } \\
\text { Informal Care }\end{array}$ & $\begin{array}{l}\text { Hours of Informal } \\
\text { care }\end{array}$ & $\begin{array}{l}\text { Requirement of } \\
\text { Informal Care }\end{array}$ & $\begin{array}{l}\text { Hours of Informal } \\
\text { care }\end{array}$ \\
\hline \multirow[t]{2}{*}{ Number of Observations } & 305 & 191 & 263 & 128 \\
\hline & OR (95\%-Cl) & Coefficient (95\%-Cl) & OR (95\%-Cl) & Coefficient (95\%-Cl) \\
\hline \multicolumn{5}{|l|}{ Age } \\
\hline Age group: $<=50$ & - & - & - & - \\
\hline Age group: 51-65 & $0.96(0.42,2.18)$ & $-0.18(-0.60,0.23)$ & $1.58(0.65,3.83)$ & $0.49(-0.10,1.08)$ \\
\hline Age group: > 65 & $1.61(0.67,3.85)$ & $-0.16(-0.60,0.29)$ & $1.81(0.71,4.61)$ & $0.53(-0.08,1.14)^{*}$ \\
\hline Ethnicity: Chinese & $1.40(0.82,2.39)$ & $0.07(-0.18,0.33)$ & $0.88(0.49,1.59)$ & $0.07(-0.29,0.42)$ \\
\hline Gender: Female & $1.41(0.78,2.54)$ & $0.27(0.001,0.55)^{* *}$ & $1.22(0.66,2.25)$ & $0.02(-0.32,0.37)$ \\
\hline Married & $1.48(0.73,3.00)$ & $-0.07(-0.38,0.24)$ & $0.81(0.40,1.64)$ & $0.07(-0.33,0.47)$ \\
\hline \multicolumn{5}{|l|}{ Ward class } \\
\hline Ward class: A\&B1 & $1.86(0.57,6.12)$ & $0.07(-0.41,0.54)$ & $2.97(0.83,10.60)^{*}$ & $0.10(-0.48,0.67)$ \\
\hline Ward class: B2 & $1.00(0.58,1.73)$ & $-0.01(-0.27,0.24)$ & $0.74(0.41,1.33)$ & $0.38(0.02,0.74)^{* *}$ \\
\hline Ward class: C & - & - & - & - \\
\hline \multicolumn{5}{|l|}{ Modified Rankin Scale } \\
\hline $\begin{array}{l}\text { Modified Rankin Scale: No symptom or } \\
\text { disability }\end{array}$ & - & - & - & - \\
\hline $\begin{array}{l}\text { Modified Rankin Scale: slight or moderate } \\
\text { disability }\end{array}$ & $2.69(1.43,5.06)^{* * *}$ & $0.30(0.02,0.58)^{* *}$ & $3.58(1.84,6.94)^{* * *}$ & $-0.35(-0.77,0.07)$ \\
\hline $\begin{array}{l}\text { Modified Rankin Scale: moderate severe or } \\
\text { severe disability }\end{array}$ & $6.33(2.44,16.40)^{* * *}$ & $0.54(0.23,0.86)^{* * *}$ & $10.63(4.33,26.05)^{* * *}$ & $-0.02(-0.43,0.40)$ \\
\hline NIHSS: moderate to severe stroke & $1.75(0.98,3.13)^{*}$ & $0.35(0.09,0.60)^{* * *}$ & NA & NA \\
\hline Hyperlipidemia & NA & NA & $1.76(0.94,3.28)^{*}$ & NA \\
\hline Depressed & $1.73(0.97,3.11)^{*}$ & NA & NA & NA \\
\hline
\end{tabular}

Notes: ${ }^{*}$ Significant at $0.10 ; *$ significant at $0.05 ; * *$ significant at 0.01

"NA" means the independent variable was not included in the parsimonious model. The independent variables were omitted in the table if they were included in none of the parsimonious model. Please refer to the Supplemental Material for the results from the full model

"- "indicates the reference category 
point, most of the factors were not associated with the hours required for informal care. Compared to patients in ward class $\mathrm{C}$, patients from ward class B2 required more hours of informal care $(\mathrm{Coef}=0.38,95 \%-\mathrm{CI}=$ $(0.02,0.74))$.

Table 4 shows the results of the factors associated with Zarit's Burden Score. Using parsimonious model, at 3 -months point, the scores were higher $(\operatorname{Coef}=0.60$, $95 \%-\mathrm{CI}=(0.29,0.91))$ for assisting informal caregivers taking care of patients with moderate severe or severe disability compared to assisting informal caregivers taking care of patients with no symptoms or disability. Assisting informal caregivers taking care of depressed patients reported higher score $(\mathrm{Coef}=0.34,95 \%-\mathrm{CI}=$
$(0.09,0.58))$. Assisting informal caregivers reported lower scores $($ Coef $=-0.34,95 \%-C I=(-0.66,-0.02))$ if the patients were married. Female assisting informal caregivers reported higher score $($ Coef $=0.39,95 \%-C I=$ $(0.04,0.75))$ as compared to male assisting informal caregivers. Compared to part-time workers, unemployed people, and retired people, full-time workers reported higher score $\quad($ Coef $=0.29,95 \%-C I=(0.05$, $0.54)$ ). If there were FDWs co-caring for the patients, the assisting informal caregivers reported lower score $($ Coef $=-0.62,95 \%-C I=(-0.97,-0.28))$. Surprisingly, hours of care provided was not associated with Zarit's Burden Score. Also, co-caring with people other than the FDWs had no impact on Zarit's Burden Score.

Table 4 Regression: Factors associated with Zarit's Burden Score - Parsimonious Model

\begin{tabular}{|c|c|c|}
\hline & 3-Months Point & 12-Months Point \\
\hline \multirow[t]{2}{*}{ Number of Observations } & 168 & 101 \\
\hline & Coefficient $(95 \%-\mathrm{Cl})$ & Coefficient $(95 \%-\mathrm{Cl})$ \\
\hline \multicolumn{3}{|l|}{ Covariates: Patients } \\
\hline \multicolumn{3}{|l|}{ Patient's Age } \\
\hline Patients' age group: $<=50$ & - & - \\
\hline Patients' age group: 51-65 & $0.25(-0.15,0.66)$ & $-0.28(-1.05,0.48)$ \\
\hline Patients' age group: > 65 & $0.24(-0.18,0.66)$ & $-0.32(-1.06,0.42)$ \\
\hline Patients' ethnicity: Chinese & $-0.05(-0.29,0.19)$ & $-0.03(-0.41,0.35)$ \\
\hline Patients' gender: Female & $0.05(-0.27,0.37)$ & $-0.43(-0.87,0.02)^{*}$ \\
\hline Patients': married & $-0.34(-0.66,-0.02)^{* *}$ & $0.27(-0.2,0.74)$ \\
\hline \multicolumn{3}{|l|}{ Ward class } \\
\hline Ward class: A\&B1 & $-0.47(-0.99,0.06)^{*}$ & $-0.02(-0.72,0.69)$ \\
\hline Ward class: B2 & $-0.07(-0.34,0.19)$ & $0.13(-0.31,0.56)$ \\
\hline Ward class: C & - & - \\
\hline \multicolumn{3}{|l|}{ Modified Rankin Scale } \\
\hline Modified Rankin Scale: No symptom or disability & - & - \\
\hline Modified Rankin Scale: slight or moderate disability & $0.27(-0.002,0.53)^{*}$ & $0.47(0.002,0.94)^{* *}$ \\
\hline Modified Rankin Scale: moderate severe or severe disability & $0.60(0.29,0.91)^{* * *}$ & $0.75(0.29,1.21)^{* * *}$ \\
\hline Hypertension & NA & $0.69(0.23,1.16)^{* * *}$ \\
\hline Depressed & $0.34(0.09,0.58)^{* * *}$ & NA \\
\hline \multicolumn{3}{|l|}{ Covariates: Caregivers } \\
\hline \multicolumn{3}{|l|}{ Caregivers' Age } \\
\hline Caregivers' age group: $<=50$ & - & - \\
\hline Caregivers' age group: 51-65 & $0.05(-0.23,0.32)$ & $0.35(-0.11,0.81)$ \\
\hline Caregivers' age group: > 65 & $-0.28(-0.64,0.09)$ & $0.33(-0.21,0.87)$ \\
\hline Caregivers' gender: Female & $0.39(0.04,0.75)^{* *}$ & $0.61(0.09,1.14)^{* *}$ \\
\hline Caregivers' work status: full-time workers & $0.29(0.05,0.54)^{* *}$ & NA \\
\hline Co-care with foreign domestic workers & $-0.62(-0.97,-0.28)^{* * *}$ & NA \\
\hline
\end{tabular}

Notes: * Significant at 0.10 ; ** significant at 0.05 ; *** significant at 0.01

Caregivers in this table means the corresponding informal caregivers who were assisting informal caregivers at the same time

"NA" means the independent variable was not included in the parsimonious model. The independent variables were omitted in the table if they were included in none of the parsimonious model. Please refer to the Supplemental Material for the results from the full model

"- "indicates the reference category 
At 12-months point, compared to assisting informal caregivers caring for patients with no symptoms or disability, assisting informal caregivers caring for patients with slight or moderate disability and moderate severe to severe disability reported higher scores. Assisting informal caregivers caring for patients having hypertension at recruitment also reported higher scores $($ Coef $=0.69$, $95 \%-\mathrm{CI}=(0.23,1.16))$. Female assisting informal caregivers reported higher scores $(\mathrm{Coef}=0.61,95 \%-\mathrm{CI}=(0.09,1.14))$.

\section{Discussion}

With the aim to examine the informal care burden poststroke and its determinants at 3-months point and 12months point, we presented a comprehensive account of informal care burden for post-stroke patients in Singapore. Overall, the number of stroke patients requiring informal care decreased over 1-year period post stroke. But for those who required informal care, they required more hours of informal care on average at 12months point.

A reasonably large proportion of stroke patients had multiple informal caregivers within the Asian context of Singapore where family caregiving is prevalent. The role played by family members in providing care to their loved ones is in line with the Singaporean principles of families being the "first line of support" with the community and government stepping in where necessary. In Southeast Asia, family is perceived as a unit comprising a web of familial social networks, centered around elderly parents and adult children residing in the same or different households; care is a functional activity (work, task) with a relational process (love, thinking, doing). Familial care (care within the family boundary) may extend beyond immediate family members [39].

At 12-months point, level of disability and dependency was found to be associated with likelihood of patients requiring informal care only, but not the hours of informal care. At 12-months point, the assisting informal caregivers could be familiar with the caring routine and become more efficient in caring the patients. The assisting informal caregivers may enter adaption phase as time passes in which they become confident in their ability to support activities of daily living [40]. The hours of informal care depends on the demand of the stroke patients as well as the efficiency level of the assisting informal caregivers. The functional dependency of the patients could have small impact on the hours of informal care by the time of 12-months point.

We reported both stroke survivor and assisting informal caregiver characteristics as significant determinants of assisting informal caregivers' perceived burden of care. Functional status as measured on the MRS was significantly associated with the Zarit's Burden Score at both 3-months point and 12-months point. In concordance with past literature [41-43], we found higher level of functional disability to be associated with higher Zarit's Burden Score as compared to stroke survivors with lower level of functional disability. It is possible that the caregiving responsibilities may increase in tandem with the functional limitations post-stroke making caregiving endeavour more intense and demanding. Moreover, it may be emotionally stressful to witness one's family member going through the challenging post-stroke recovery trajectory. Together these may influence the assisting informal caregiver's appraisal of their caregiving role. Stroke survivor's depressive symptoms were significantly associated with the Zarit's Burden Score at 3-months point. This is consistent with existing literature reporting significant association between stroke survivor's and caregiver's mental health $[9,19]$. We found presence of hypertension in patients was associated with informal caregivers reporting higher caregiving burden. Possible explanation could be related to additional care needs associated with having a comorbid condition like hypertension. Significant association between patients' increasing level of comorbidity and informal caregiver burden has been reported in patients with cognitive impairment [44].

The informal caregiver characteristics found significant in current analysis seem to reflect the unique caregiving landscape of Singapore, with caregiving responsibilities shared among FDWs and family informal caregivers. Co-care with FDWs was associated with lower Zarit's Burden Score at 3-months point only and not at 12months point. It is well-known that first 3 months poststroke are more challenging for the caregivers as they familiarize themselves with the new caregiving responsibilities and the uncertain care needs of the stroke survivors $[29,45]$. Thus, assistance from FDWs may play a relatively more crucial role in the early post-stroke period as compared to late post-stroke period. Similar to our finding. Chong and colleagues [46] reported FDWs as a moderator of distress in caregivers of frail elders. While co-care with FDWs was significantly associated with lower Zarit's Burden Score, co-care with other assisting informal caregivers was not significantly associated with Zarit's Burden Score. Possible explanations could be related to the broad scope of duties performed by the FDWs within their employer's home, ranging from providing childcare, eldercare to engaging in other household chores [47]. Thus, FDWs may help with competing commitments of the assisting informal caregiver, resulting in reduced overall strain on the assisting informal caregiver. This facilitation role of the FDWs, also described as "an important coping resource for caregivers" and contributing to "lessen the intensity of stressors" in literature [48], may or may not be replicated in co-care by family members, as family members may 
primarily want to be engaged in caregiving responsibilities. The significance of our finding is further highlighted by the fact that caregivers receiving assistance from FDWs during first 3 months is also associated with improved stroke survivor outcomes [25].

We found married stroke survivors had assisting informal caregivers reporting lower caregiver burden at 3 -months point as compared to their unmarried counterparts. The protective effect of marital status on health outcomes of both stroke [49] and non-stroke population [50] has been reported in past literature. Moreover, within the stroke population, Liu and colleagues [51] recently reported married stroke survivors having favourable outcomes post-stroke as compared to those unmarried. It may be possible that married stroke survivors with lower stroke related disability and recurrence may have relatively lower care needs resulting in lower perceived burden by their caregivers.

Female assisting informal caregivers reported higher Zarit's Burden Score at both 3-months point and 12months point. Similar results have been reported in the literature [52, 53]. Female assisting informal caregivers may take on more challenging and tedious caregiving duties resulting in higher caregiver burden as compared to their male counterparts. At 3-months point, full-time workers reported higher score compared to part-time workers, unemployed and retired. Full-time workers may experience Double-burden effect due to competing commitments required from work and caring for stroke patients [54, 55].

Adopting a comprehensive approach, we conceptualized burden of informal care for current study to include both objective ("number of hours of care") and subjective ("Zarit's Burden Score") components. This not only enabled us to report the significant determinants of both objective and subjective burden of informal care, but also explore the relationship between the two. Interestingly, we found no significant association between hours of care and Zarit's Burden Score, which is contrary to the findings of some researchers $[10,18,20]$. One possibility could be related to the differences between objective and subjective caregiving burden estimates. The latter comprises of caregiver's appraisal of the caregiving role, which often incorporates other parameters like role limitations due to mental or physical health of caregivers [56], sense of coherence [57], competing commitments of the caregivers, etc. In fact, in a non-stroke population, the association between objective and subjective caregiver burden was reported to be "complex", with subjective caregiver burden encompassing not just the amount of caregiving but also the caregiver-care recipient relationship dynamics [58]. Also, it is important to note that hours of caregiving solely may not be indicative of the caregiving burden, and the nature of caregiving denoted by the constituting caregiving tasks [41] may be more strongly associated with perceived caregiving burden. While we did not capture caregiving hours spent on specific caregiving tasks in current study, we recommend future research efforts capture both hours of caregiving and specific caregiving activities to further expand on our findings. The burden due to different activities could differ, for example comparing bathing and shower to taking medicine. In the scenario of multiple informal caregivers being available, overall burden of informal care could be reduced by optimal allocation of types of assistance. Although we found that "number of hours of care" was not associated with "Zarit's Burden Score", it is important to acknowledge that both are important for policy making. "Number of hours of care" has financing and economic implications while informal caregiver burden is a strong determinant of caregiver burnout, caregiver abuse and premature admission to nursing home which itself has financing and economic implications.

Using a yearlong cohort consisting of stroke patients and their informal caregivers in Singapore, our study contributed to the existing literature of burden of informal care due to stroke considering an Asian setting. Our study documented some unique results including the prevalence of multiple informal caregivers and FDWs. We also observed results that were different from the literature, e.g.: hours of informal care was not associated with informal caregivers' subjective burden. Further study could be conducted to understand the reasons. While generalizability of findings related to co-care with FDWs may be limited to similar settings as Singapore (where FDWs are a common occurrence), most of the other findings of our study have relatively greater generalizability. Findings related to association between functional status post-stroke and caregiver burden, gender of informal caregiver and marital status of stroke survivors are generalizable to other settings.

Our study has several limitations. First, corresponding informal caregivers reported the hours of informal care provided by all the assisting informal caregivers. But, efforts were made to minimize the recall bias and collect high quality data including training the data collectors, using standardised questionnaire and forms, and setting the recall period as 3 months. Second, patients selfreported whether they were depressed. Third, though efforts were made to follow up the participants in S3, not all the recruited patients who were alive at 3-months point and 12-months point were followed up. Overall mortality rate was less than $5 \%$, which is unlikely to introduce a selection bias [29]. For the patients included in the analysis, most of the demographic characteristics and clinical characteristics were similar at recruitment, at 3-months point, and at 12-months point as shown in Table 1. Married patients were more likely to be followed up, which could be due to the fact that spouse 
plays an important role in informal care. Chinese patients were less likely to be followed up. Future studies can investigate this issue. Furthermore, compared to the patients at recruitment, smaller proportion of patients, lower by around 5\%, were with NIHSS indicating "No stroke symptom or minor stroke" at 3-months and 12months point. One potential explanation is that patients who were lost to follow up were those who did not require informal care or required low level of informal care. In such a case, patients with low NIHSS and who required low level of informal care were more likely lost to follow-up and omitted from our sample, which can lead to overestimation of overall informal care burden and underestimation of the association between NIHSS and informal care burden. Fourth, we focused on examining the factors associated with the likelihood of patients requiring informal care, hours of informal care required and the care burden of informal caregivers broadly. We did not explore the detailed explanations and causal pathways behind. Further work should be conducted to better understand this. However, our work can serve as a road map to guide such work. Fifth, the care burden of FDWs were not examined, as FDWs were not eligible to be corresponding informal caregivers. Future studies can address this gap.

\section{Conclusions}

Our study shows informal care burden remains high up to 12 -months point post-stroke. Both patient factors and informal caregiver factors were associated with likelihood of requiring informal care, hours of informal care required, and subjective caregivers' burden. Our results provide empirical evidence for policymakers to consider when designing polices to support patients and informal caregivers in post-stroke caregiving in the community.

\section{Abbreviations}

Cl: confidence interval; Coef: coefficient; FDW: foreign domestic worker; MRS: Modified Rankin Scale; NIHSS: National Institute of Health Stroke Scale; OR: odds ratio; S3: Singapore Stroke Study

\section{Supplementary Information}

The online version contains supplementary material available at https://doi. org/10.1186/s12889-021-11991-3.

Additional file 1

\section{Acknowledgements}

We would like to thank the medical staff at the public tertiary hospitals for assisting with the recruitment of patients and their caregivers. We would also like to thank all the participants in our study for their participation and cooperation.

\section{Authors' contributions}

YW was involved in conceptualization and design of the study, analysis and interpretation of data, original draft preparation and incorporating revisions in manuscript based on critical inputs from other co-authors. ST was involved in conceptualization and design of the study, interpretation of data and drafting of the manuscript. HH made substantial contributions to conception and design of the study specifically with provision of expertise in medical domain and was involved in revising the manuscript critically for intellectual content. KEL was involved in acquisition of data and in revising the manuscript critically for intellectual content. NV was involved in acquisition of data and in revising the manuscript critically for intellectual content. EM was involved in acquisition of data and in revising the manuscript critically for intellectual content. DADS was involved in acquisition of data and in revising the manuscript critically for intellectual content. PY was involved in acquisition of data and in revising the manuscript critically for intellectual content. BYT was involved in acquisition of data and in revising the manuscript critically for intellectual content. SHY was involved in acquisition of data and in revising the manuscript critically for intellectual content. YSN was involved in acquisition of data and in revising the manuscript critically for intellectual content. TMT was involved in acquisition of data and in revising the manuscript critically for intellectual content. YHA was involved in acquisition of data and in revising the manuscript critically for intellectual content. KHK was involved in acquisition of data and in revising the manuscript critically for intellectual content. RS was involved in acquisition of data and in revising the manuscript critically for intellectual content. RAM was involved in acquisition of data and in revising the manuscript critically for intellectual content. HMC was involved in acquisition of data and in revising the manuscript critically for intellectual content. CN was involved in acquisition of data and in revising the manuscript critically for intellectual content. AC was involved in acquisition of data and in revising the manuscript critically for intellectual content. GCHK was involved in conceptualization and design of the study, acquisition of data, interpretation of data, drafting of the manuscript, and providing critical inputs to revision of manuscript along with supervision of the study. All the authors have read and approved the final version of the manuscript to be published and are agreeable to take accountability of all aspects of the work involved in the manuscript.

\section{Funding}

This research is supported by the Singapore Ministry of Health's National Medical Research Council under the Centre Grant Programme - Singapore Population Health Improvement Centre (NMRC/CG/C026/2017_NUHS).

\section{Availability of data and materials}

The anonymized data that support the findings of this study are available from the corresponding author upon reasonable request.

\section{Declarations}

Ethics approval and consent to participate

S3 was approved by the National University of Singapore Institutional Review Board, SingHealth Centralized Institutional Review Board and the National Health Group Domain Specific Review Board.

Informed consent was obtained from all participants. Research involving human participants was performed in accordance with the Declaration of Helsinki and was approved by an appropriate ethics committee.

\section{Consent for publication}

Not Applicable.

\section{Competing interests}

All authors have no conflict of interest to declare.

\section{Author details}

'Saw Swee Hock School of Public Health, National University of Singapore, 12 Science Drive 2, \#10-01, Singapore 117549, Singapore. ${ }^{2}$ Physical Medicine and Rehabilitation Service, Durham VA Medical Centre, 508 Fulton St, Durham, NC 27705, USA. ${ }^{2}$ Lee Kim En Neurology Pte Ltd, Mount Elizabeth, \#11-14/15, Mount Elizabeth Medical Centre, Singapore 228510, Singapore. ${ }^{4}$ Raffles Neuroscience Centre, Raffles Hospital, 585 North Bridge Rd, Level 9 Raffles Specialist Centre, Singapore 188770, Singapore. ${ }^{5}$ St. Andrew's Community Hospital, 8 Simei Street 3, Singapore 529895, Singapore. ${ }^{6}$ National Neuroscience Institute, Singapore General Hospital campus, $11 \mathrm{Jln}$ Tan Tock Seng, Level 1, Singapore 308433, Singapore. ${ }^{7}$ Dept of Geriatric Medicine, Khoo Teck Puat Hospital, 90 Central Yishun, Singapore 768828, Singapore. ${ }^{8}$ St. Luke's Hospital, 2 Street 11 Bukit Batok, Singapore 659674, Singapore. 'Department of Rehabilitation Medicine, Changi General Hospital, 2 Simei Street 3, Singapore 529889, Singapore. ${ }^{10}$ Department of Rehabilitation Medicine, Singapore General Hospital, Outram Rd, Singapore 
169608, Singapore. ${ }^{11}$ Department of Neurology, National Neuroscience Institute, Neurology, Tan Tock Seng Hospital, 11 Jln Tan Tock Seng, Level 1, Singapore 308433, Singapore. ${ }^{12}$ Department of Rehabilitation Medicine, Tan Tock Seng Hospital, 11 Jln Tan Tock Seng, Singapore 308433, Singapore. ${ }^{13}$ Department of Medicine, Yong Loo Lin School of Medicine, National University of Singapore, 10 Medical Dr, Singapore 117597, Singapore.

${ }^{14}$ Department of Neurosurgery, National University Hospital, 5 Lower Kent Ridge Rd, Singapore 119074, Singapore.

\section{Received: 16 February 2021 Accepted: 6 October 2021}

\section{Published online: 26 October 2021}

\section{References}

1. Roth GA, Abate D, Abate KH, Abay SM, Abbafati C, Abbasi N, et al Global, regional, and national age-sex-specific mortality for 282 causes of death in 195 countries and territories, 1980-2017: a systematic analysis for the global burden of disease study 2017. Lancet. 2018:392:1736-88. https://doi.org/10.1 016/S0140-6736(18)32203-7, 10159

2. Kang HY, Lim SJ, Suh HS, Liew D. Estimating the lifetime economic burden of stroke according to the age of onset in South Korea: a cost of illness study. BMC Public Health. 2011;11(1):646. https://doi.org/10.1186/1471-24 58-11-646.

3. Saka O, McGuire A, Wolfe C. Cost of stroke in the United Kingdom. Age Ageing. 2009;38(1):27-32. https://doi.org/10.1093/ageing/afn281.

4. Chevreul K, Durand-Zaleski I, Gouepo A, Fery-Lemonnier E, Hommel M, Woimant F. Cost of stroke in France. Eur J Neurol. 2013;20(7):1094-100. https://doi.org/10.1111/ene.12143.

5. Wang G, Zhang Z, Ayala C, Dunet DO, Fang J, George MG. Costs of hospitalization for stroke patients aged 18-64 years in the United States. J Stroke Cerebrovasc Dis. 2014;23(5):861-8. https://doi.org/10.1016/j. jstrokecerebrovasdis.2013.07.017.

6. Gloede TD, Halbach SM, Thrift AG, Dewey HM, Pfaff H, Cadilhac DA. Long term costs of stroke using 10-year longitudinal data from the north East Melbourne stroke incidence study. Stroke. 2014;45(11):3389-94. https://doi. org/10.1161/strokeaha.114.006200.

7. Venketasubramanian N, Chen CLH. Burden of stroke in Singapore. Int J Stroke. 2008;3(1):51-4. https://doi.org/10.1111/j.1747-4949.2008.00181.x.

8. Ng CS, Toh MPHS, Ng J, Ko Y. Direct medical cost of stroke in Singapore. Int J Stroke. 2015;10(SA100):75-82. https://doi.org/10.1111/ijs.12576.

9. Tooth L, McKenna K, Barnett A, Prescott C, Murphy S. Caregiver burden, time spent caring and health status in the first 12 months following stroke. Brain Inj. 2005;19(12):963-74. https://doi.org/10.1080/02 699050500110785

10. Oliva-Moreno J, Peña-Longobardo LM, Mar J, Masjuan J, Soulard S, Gonzalez-Rojas N, et al. Determinants of informal care, burden, and risk of burnout in caregivers of stroke survivors the CONOCES study. Stroke. 2018; 49(1):140-6. https://doi.org/10.1161/STROKEAHA.117.017575.

11. Oliva-Moreno J, Trapero-Bertran M, Peña-Longobardo LM, del Pozo-Rubio R. The valuation of informal Care in Cost-of-Illness Studies: a systematic review. Pharmacoeconomics. 2017;35(3):331-45. https://doi.org/10.1007/s40273-0160468-y.

12. Hoefman RJ, Van Exel J, Brouwer W. How to include informal care in economic evaluations. Pharmacoeconomics. 2013;31(12):1105-19. https:// doi.org/10.1007/s40273-013-0104-z.

13. Rajsic S, Gothe H, Borba HH, Sroczynski G, Vujicic J, Toell T, et al. Economic burden of stroke: a systematic review on post-stroke care. Eur J Health Econ. 2019;20(1):107-34. https://doi.org/10.1007/s10198-018-0984-0.

14. Youman P, Wilson K, Harraf F, Kalra L. The economic burden of stroke in the United Kingdom. Pharmacoeconomics. 2003;21(Supplement 1):43-50. https://doi.org/10.2165/00019053-200321001-00005.

15. Joo H, Wang G, Yee SL, Zhang P, Sleet D. Economic burden of informal caregiving associated with history of stroke and falls among older adults in the U.S. Am J Prev Med. 2017;53(6):S197-204. https://doi.org/10.1016/j.a mepre.2017.07.020

16. Joo H, Dunet DO, Fang J, Wang G. Cost of informal caregiving associated with stroke among the elderly in the United States. Neurology. 2014;83(20): 1831-7. https://doi.org/10.1212/wnl.0000000000000986

17. Van Exel NJA, Koopmanschap MA, Van Den Berg B, Brouwer WBF, Van Den Bos GAM. Burden of informal caregiving for stroke patients: identification of caregivers at risk of adverse health effects. Cerebrovasc Dis. 2005;19(1):11-7. https://doi.org/10.1159/000081906.
18. Bugge C, Alexander H, Hagen S. Stroke patients' informal caregivers: patient, caregiver, and service factors that affect caregiver strain. Stroke. 1999;30(8): 1517-23. https://doi.org/10.1161/01.STR.30.8.1517.

19. McCullagh E, Brigstocke G, Donaldson N, Kalra L. Determinants of caregiving burden and quality of life in caregivers of stroke patients. Stroke. 2005; 36(10):2181-6. https://doi.org/10.1161/01.STR.0000181755.23914.53.

20. Gbiri CA, Olawale OA, Isaac SO. Stroke management: informal caregivers' burdens and strians of caring for stroke survivors. Ann Phys Rehabil Med. 2015;58(2):98-103. https://doi.org/10.1016/j.rehab.2014.09.017.

21. Jones AL, Charlesworth JF, Hendra TJ. Patient mood and carer strain during stroke rehabilitation in the community following early hospital discharge. Disabil Rehabil. 2000;22(11):490-4. https://doi.org/10.1080/096382800413970.

22. Morimoto T, Schreiner AS, Asano H. Caregiver burden and health-related quality of life among Japanese stroke caregivers. Age Ageing. 2003;32(2): 218-23. https://doi.org/10.1093/ageing/32.2.218.

23. Mandowara B, Patel AN, Amin AA, Phatak A, Desai S. Burden faced by caregivers of stroke patients who attend rural-based medical teaching hospital in western India. Ann Indian Acad Neurol 2020;23:38-43. https:// doi.org/10.4103/aian. AIAN_406_18, 1.

24. Kurtulus Tosun Z, Professor A, Temel M, Kemal Mahallesi N, Caddesi K. Burden of caregiving for stroke patients and the role of social support among family members: an assessment through home visits. Int J Caring. 2017;10:1696-704

25. Tyagi S, Koh GCH, Luo N, Tan KB, Hoenig H, Matchar DB, et al. Dyadic approach to post-stroke hospitalizations: role of caregiver and patient characteristics. BMC Neurol. 2019;19(1):267. https://doi.org/10.1186/s12883019-1510-4.

26. Tyagi S, Koh GCH, Nan L, Tan KB, Hoenig H, Matchar DB, et al. Healthcare utilization and cost trajectories post-stroke: role of caregiver and stroke factors. BMC Health Serv Res. 2018;18(1):881. https://doi.org/10.1186/s12913018-3696-3.

27. Tam WJ, Koh GCH, Legido-Quigley H, Ha NHL, Yap PLK. I Can't do this alone: a study on foreign domestic workers providing long-term care for frail seniors at home. Int Psychogeriatrics. 2018;30(9):1269-77. https://doi. org/10.1017/S1041610217002459.

28. Østbye T, Malhotra R, Malhotra C, Arambepola C, Chan A. Does support from foreign domestic workers decrease the negative impact of informal caregiving? Results from Singapore survey on informal caregiving. J Gerontol - Ser B Psychol Sci Soc Sci. 2013;68(4):609-21. https://doi.org/10.1 093/geronb/gbt042.

29. Tyagi S, Koh GCH, Luo N, Tan KB, Hoenig H, Matchar DB, et al. Dyadic approach to supervised community rehabilitation participation in an Asian setting post-stroke: exploring the role of caregiver and patient characteristics in a prospective cohort study. BMJ Open. 2020;10(4):e036631. https://doi.org/10.1136/bmjopen-2019-036631.

30. Seng BK, Luo N, Ng WY, Lim J, Chionh HL, Goh J, et al. Validity and reliability of the Zarit burden interview. Ann Acad Med Singap. 2010;39: 758-63.

31. Bédard M, Molloy DW, Squire L, Dubois S, Lever JA, O'donnell M. The Zarit burden interview: a new short version and screening version. Gerontologist. 2001:41(5):652-7. https://doi.org/10.1093/geront/41.5.652.

32. Singapore PY-AAM, 2010 undefined. Validity and reliability of the Zarit Burden Interview in assessing caregiving burden. n.d.

33. Stagg B, Larner AJ. Zarit burden interview: pragmatic study in a dedicated cognitive function clinic. Prog Neurol Psychiatry. 2015;19(4):23-7. https://doi. org/10.1002/pnp.390.

34. Yu J, Yap P, Liew TM. The optimal short version of the Zarit burden interview for dementia caregivers: diagnostic utility and externally validated cutoffs. Aging Ment Heal. 2019;23(6):706-10. https://doi.org/10.1080/13 607863.2018.1450841

35. Gratão ACM, Brigola AG, Ottaviani AC, Luchesi BM, Souza ÉN, Rossetti ES, Oliveira NA, Terassi M, Pavarini SCI Brief version of Zarit burden interview (ZBI) for burden assessment in older caregivers. Dement e Neuropsychol 2019;13:122-129. https://doi.org/10.1590/1980-57642018dn13-010015, 1.

36. Kwon S, Hartzema AG, Duncan PW, Lai SM. Disability measures in stroke: relationship among the Barthel index, the functional Independence measure, and the modified Rankin scale. Stroke. 2004;35(4):918-23. https:// doi.org/10.1161/01.STR.0000119385.56094.32.

37. Kasner SE. Clinical interpretation and use of stroke scales. Lancet Neurol 2006:5:603-612. https://doi.org/10.1016/S1474-4422(06)70495-1, 7.

38. StataCorp L. Stata statistical software: release 16. TX: College Station; 2019. 
39. Wongboonsin P, Tan J. Care relations in Southeast Asia: the family and beyond. Brill. 2018. https://doi.org/10.1163/9789004384330.

40. Cameron Jl, Gignac MAM. "Timing it right": a conceptual framework for addressing the support needs of family caregivers to stroke survivors from the hospital to the home. Patient Educ Couns. 2008;70(3):305-14. https:// doi.org/10.1016/j.pec.2007.10.020.

41. Oni O, Olagunju A, Okpataku C, Erinfolami A, Adeyemi J. Predictors of caregiver burden after stroke in Nigeria: effect on psychosocial well-being. Indian J Psychiatry 2019;61:457-464. https://doi.org/10.4103/psychiatry. IndianJPsychiatry_395_18, 5.

42. Zhu W, Jiang Y. Determinants of caregiver burden of patients with haemorrhagic stroke in China. Int J Nurs Pract. 2019;25(2):e12719. https:// doi.org/10.1111/ijn.12719.

43. Flyckt $L$, Fatouros-Bergman $H$, Koernig T. Determinants of subjective and objective burden of informal caregiving of patients with psychotic disorders. Int J Soc Psychiatry. 2015;61 (7):684-92. https://doi.org/10.1177/002 0764015573088

44. Dauphinot V, Ravier A, Novais T, Delphin-Combe F, Moutet C, Xie J, et al. Relationship between comorbidities in patients with cognitive complaint and caregiver burden: a cross-sectional study. J Am Med Dir Assoc. 2016; 17(3):232-7. https://doi.org/10.1016/j.jamda.2015.10.011.

45. Lutz BJ, Young M, Cox KJ, Martz C, Creasy KR. The crisis of stroke: experiences of patients and their family caregivers. Top Stroke Rehabil. 2011;18(6):786-97. https://doi.org/10.1310/tsr1806-786.

46. Chong AML, Kwan CW, Chi I, Lou WWQ, Leung AYM. Domestic helpers as moderators of spousal caregiver distress. Journals Gerontol - Ser B Psychol Sci Soc Sci. 2014;69(6):966-72. https://doi.org/10.1093/geronb/gbu034.

47. Yeoh BSA, Huang S. Foreign domestic workers and home-based care for elders in Singapore. J Aging Soc Policy. 2010;22(1):69-88. https://doi.org/1 0.1080/08959420903385635.

48. Basnyat I, Chang L. Examining live-in foreign domestic helpers as a coping resource for family caregivers of people with dementia in Singapore. Health Commun. 2017;32(9):1171-9. https://doi.org/10.1080/1 0410236.2016 .1220346

49. Dupre ME, Lopes RD. Marital history and survival after stroke. J Am Heart Assoc. 2016;5(12). https://doi.org/10.1161/JAHA.116.004647.

50. Manzoli L, Villari P. M Pirone G, Boccia A. Marital status and mortality in the elderly: a systematic review and meta-analysis. Soc Sci Med 2007;64:77-94. https://doi.org/10.1016/j.socscimed.2006.08.031, 1.

51. Liu Q, Wang X, Wang Y, Wang C, Zhao X, Liu L, et al. Association between marriage and outcomes in patients with acute ischemic stroke. J Neurol. 2018;265(4):942-8. https://doi.org/10.1007/s00415-018-8793-z.

52. Zhu W, Jiang Y. A Meta-analytic study of predictors for informal caregiver burden in patients with stroke. J Stroke Cerebrovasc Dis. 2018;27(12):363646. https://doi.org/10.1016/j.jstrokecerebrovasdis.2018.08.037.

53. Larson J, Franzén-Dahlin Å, Billing E, von Arbin M, Murray V, Wredling R. The impact of gender regarding psychological well-being and general life situation among spouses of stroke patients during the first year after the patients' stroke event: a longitudinal study. Int J Nurs Stud. 2008;45(2):25765. https://doi.org/10.1016/j.jinurstu.2006.08.021.

54. Schmitz H, Stroka MA. Health and the double burden of full-time work and informal care provision - evidence from administrative data. Labour Econ. 2013;24:305-22. https://doi.org/10.1016/j.labeco.2013.09.006

55. Chen L, Fan H, Chu L. The Double-Burden Effect: Does the Combination of Informal Care and Work Cause Adverse Health Outcomes Among Females in China? vol. 32. SAGE Publications Inc.; 2020. https://doi.org/10.1177/08982 64320910916.

56. Fekete C, Tough H, Siegrist J, Brinkhof MWG. Health impact of objective burden, subjective burden and positive aspects of caregiving: an observational study among caregivers in Switzerland. BMJ Open. 2017;7(12): e017369. https://doi.org/10.1136/bmjopen-2017-017369.

57. Zhu W, Jiang Y. A Meta-analytic study of predictors for informal caregiver burden in patients with stroke. J Stroke Cerebrovasc Dis. 2018;27(12):363646. https://doi.org/10.1016/j.jstrokecerebrovasdis.2018.08.037.

58. Jones SL. The association between objective and subjective caregiver burden. Arch Psychiatr Nurs 1996;10:77-84. https://doi.org/10.1016/508839417(96)80070-7, 2.

\section{Publisher's Note}

Springer Nature remains neutral with regard to jurisdictional claims in published maps and institutional affiliations.

\section{Ready to submit your research? Choose BMC and benefit from:}

- fast, convenient online submission

- thorough peer review by experienced researchers in your field

- rapid publication on acceptance

- support for research data, including large and complex data types

- gold Open Access which fosters wider collaboration and increased citations

- maximum visibility for your research: over $100 \mathrm{M}$ website views per year

At $\mathrm{BMC}$, research is always in progress.

Learn more biomedcentral.com/submissions 